\title{
Portfolio Heuristics, Linearity, and Qualitative Analysis
}

\author{
Manuel Tarrazo ${ }^{1}$ \\ ${ }^{1}$ School of Management, University of San Francisco. 2130 Fulton St, San Francisco, CA, USA. \\ Correspondence: Manuel Tarrazo, PhD, School of Management, University of San Francisco. 2130 Fulton St, San \\ Francisco, CA, USA.
}

Received: July 11, 2016

Accepted: August 4, 2016

Available online: August 12, 2016

doi:10.11114/aef.v3i4.1802

URL: http://dx.doi.org/10.11114/aef.v3i4.1802

\begin{abstract}
Linearity can be used to introduce qualitative analysis in portfolio optimization using very specific heuristics which in some cases carries enough information to anticipate the entire (qualitative) rank of solutions. This result is shown in the first part of our study. In the second part we show that correct analysis of optimal portfolios, and in particular those minimizing portfolio variance, requires complementary quantitative analysis with qualitative analysis as not all efficient portfolios have the same return-to-risk quality, and those minimizing variance may not minimize risk. In this section, we also introduce some notes of caution on the application of heuristics when applied to portfolios calculated in non-standard ways. The third and last section extends the literature by critically reviewing different ways in which qualitative heuristics can complement portfolio selection methods while also reviewing existing, full-fledged qualitative portfolio optimization methodologies.
\end{abstract}

Keywords: Portfolio analysis, mean-variance, qualitative analysis, heuristics.

\section{Introduction}

This paper focuses on developing qualitative portfolio analyses. It has been motivated by Barone-Adesi's (2007) interesting contribution, and also by our own current research program.

Barone-Adesi (2007) stresses the importance of linearity in portfolio optimization and how it may be exploited to develop heuristics with practical investing value. Heuristics are decision rules that allow individuals to make complex judgments more simply (Tversky and Kahneman, 1974). In fact, Hambrick and Mason (1984) and Mintzberg, Rasinghani, and Theoret (1976) note that decisions may vary with the characteristics of the decision maker. Barone-Adesi's specific contribution centers on the analysis of the properties of certain optimal portfolios (single-index, equally weighted portfolio) and their corresponding linear heuristics. His more general contribution, however, is about adding flexibility to current portfolio optimizations by better use of their implied heuristics. This is most interesting because heuristics may carry qualitative information that is generally neglected by existing approaches. We reasoned that a portfolio manager's mindset or heuristic may influence or restrict the ultimate decision taken among multiple choices. Barone-Adesi's contribution could not be timelier. Currently, there are several intense and multidisciplinary research streams converging on investing: enhancing decision making with all possible available information (finance and economics), understanding choice and its psychological aspects (psychology), developing methodologies and processing tools to encompass information of a different nature (computer science), and building optimization procedures that are best suited to process that information (operations research).

It is easy to appreciate that advancement in investing requires the integration of quantitative and qualitative information, not only because of its interdisciplinary foundations, but also because investing decisions are entirely forward-looking and information about the future is never complete and is made up of multiple and various components. Take, for example, the case of venture capital and initial public offerings. The experience in recent issues such as that of Facebook and Groupon reveals that something has changed compared to the times of Netscape (IPO, 1995), when numbers were weighted heavily in pre-IPO analyses; and also from those times at the end of the dot.com boom of the 1990's, when companies were taken public with little or no track-record (e.g., Webvan, 1999; Pets.com, 2000; eToys.com, 2001). Lack of track-record means some quantitative indicators are simply not available. Further, the intense process of change suggests indicators (e.g., number of times mentioned in the press) that may help investors decide their strategies. 
Consider the case where two ventures may be pitched to private investors and each of them may include the same amount of quantitative forecasts; yet, investors may base their decisions on qualitative elements and prefer one to the other. Prior research lends support to this argument. For example, Khan (1987) found that VCs tend to be intuitive decision makers. Zacharakis and Shepherd (2001) found that VCs (venture capitalists) tend to be overconfident and this over confidence tends to decrease their decision making accuracy. Shepherd, Zacharakis and Baron (2003) found that as VCs become experienced beyond a certain point, their decision accuracy tends to diminish, possibly due to the further engraining of their mindset due to prior successful experiences. Their findings imply the existence of a firm-level heuristic. Heuristics at the firm level may be viewed as the dominant logic of the firm (Prahalad and Bettis, 1986), that is, a mind set, or a conceptualization of the business.

In our study, we will clarify, complement, and extend Barone-Adesi's line of research on linear heuristics and portfolio optimization, which shows that linearization may be helpful even in nonlinear cases. In the first section of this note we will clarify mean-variance portfolio optimization and, specifically observe why one security is preferred over another, and why certain optimal weights are larger than others. In this section we will also face the issue of non-negativity on optimal weights: In other words, why some securities will never be chosen in the optimization. In the second section of the paper we complement Barone-Adesi's analysis by focusing on three key items. First, we will show what exactly happens along the so-called efficient frontier, which represents all the portfolios worth being considered by the investor. Very importantly, we show why and how some of these portfolios are qualitatively better/worse than others. Second, we will note that some caution is needed when deriving useful heuristics. The last section closes the study by enumerating areas and procedures of great promise, not only to develop qualitatively-oriented heuristics, but also to take portfolio analysis on the whole to higher levels of application. In this pursuit we highlight two particular items: 1) portfolio metaheuristics, and 2) relational equations possibilistic modeling. Our analysis strengthens Barone-Adesi's argument to further study the potential of linear-heuristics, and it also suggests that other approaches of wider scope are also capable of enhancing research, individual decision making, and general investment practice.

We foresee two types of readers of this article. One may have a general acquaintance with portfolio theory and focus on the qualitative analysis perspectives. The other reader may be a specialist in portfolio optimization and quantitative methods. We will try to present our research in a logical, non-mathematical, and practical manner that will lead the first reader through our exposition while also providing to the second reader, we hope, new practical insights.

\section{Detail and Clarifications on Mean-Variance Portfolio Optimization}

Portfolio optimization is one of the gems in financial decision-making. It reflects many years of integration of different tributary areas such as demand analysis, markets, macroeconomics, decision making and risk tolerance, and optimization. Markowitz (1952) and Roy (1952) represented the first analyses that were comprehensive enough to reflect the extant knowledge capable of practical application. Markowitz (1952) was particularly successful at communicating the major components of portfolio selection and providing a reasonable way to proceed. Briefly put, the return on each investment (especially stocks) could be taken as a random variable exhibiting critical statistical regularities -i.e., mean, representing expected returns; and variance, representing risk. The investor would then proceed as follows: 1) obtain closing prices for some securities, 2) compute returns and their means and variance-covariance numbers, and 3) find the portfolio that provides the investor's desired return-to-risk ratio. This was more easily said than done during the 1950's. A great deal of research was needed to find the appropriate optimization algorithm (using nonlinear programming), and the computing power for a modest 25 -security portfolio could only be found at state-of-the-art astronomical research facilities, (Markowitz 1959, p. 383). In retrospective, Roy (1952) seems as interesting as Markowitz (1952); The author used closing prices rather than returns, as well as a number of practical features (e.g., a safety price-margin). But his analysis also revealed an intimidating analytical instrument, while Markowitz opted for a graphical discussion of his method that made it appear far more comprehensible.

Additional detail on the genesis and evolution of portfolio theory can be found in Rubinstein (2002). Two excellent overviews are those of Constantinides and Malliaris (1995) and Steinbach (2001); the former focuses on financial theory, the latter on mathematical and analytical aspects. Fabozzi, Gupta, and Markowitz (2002) evaluate the many challenges and decisions we must make when applying portfolio optimization portfolio (e.g., number of securities, frequency, data length, and so forth). Tarrazo (2014) studies mean-variance analysis and each of its constitutive parts to clarify what optimizations do, which is still unclear for many researchers, students, and actual investors. This is the case because, throughout its history, portfolio theory has been hard to understand, perhaps due to the following reasons: 1) the problem carried unnecessary analytical burden because of what Steinbach (2001) called "inessential generality" (e.g., inequalities rather than equalities, restrictions that end up being non-binding at the optimal), 2) it used constructs that complicate matters further (e.g. utility theory), and 3) mathematical programming was being used to find solutions. As Geoffrion (1976) has noted, although mathematical programming finds solutions but it does not explain how optimal solutions are obtained. Knowing what portfolio optimization does, however, is unavoidable, if we want to enhance 
current portfolio optimizations with qualitative analysis. In other words, it is not possible to ascertain the value of any addition to portfolio selection if we do not know how solutions are obtained using current methods.

Tarrazo (2014) demonstrates how portfolio optimization boils down to a straightforward arbitrage rule set in a linear decision framework. The linear rule can be thought of a very special "heuristic" because, in some cases, it perfectly anticipates the order of the optimal solution (qualitative rankings), and in all cases helps the optimization effort. Exhibit I presents an example of portfolio optimizations. The top of the exhibit shows the simultaneous equation system, representing the first order conditions (FOC) of the optimization of the objective function in portfolio optimization, both of which are represented by equations (1) and (2).

$$
\begin{array}{lc}
\text { Objective function: } & F(x)=-1 / 2 x^{\prime} A x+x^{\prime} b \\
\text { First order conditions: } & A x=b
\end{array}
$$

Where, $\mathrm{x}$ is a vector of portfolio weights, $\mathrm{A}$ is the variance-covariance matrix, and $\mathrm{b}$ is a vector representing mean returns. These variables have dimension $\mathrm{n}$ at the beginning of the optimization, and $\mathrm{k}(\mathrm{k} \leq \mathrm{n})$ when the optimization is completed successfully. Portfolio figures are calculated by first computing optimal portfolio weights $w i^{*}=\mathrm{xi}^{*} / \Sigma \mathrm{xi}^{*}$, which insures $\Sigma \mathrm{xi}^{*}=1$ (full investment assumption); after which one calculates portfolio returns, $\mathrm{rp}=\mathrm{w}^{\prime} \mathrm{b}$, and portfolio variance, varp $=\mathrm{w}^{\prime} \mathrm{A} \mathrm{w}$.

Equations (1) and (2) represent the algebraic approach to portfolio optimization, where the magnitudes of interest are captured by a quadratic equation ( $\mathrm{x}^{\prime} \mathrm{A} \mathrm{x}$ is the quadratic form associated with the quadratic equation). Mathematical programming is not needed because optimization of the quadratic equation maximizes the return-to-risk ratio (rp/varp) of the portfolio, as is desired in portfolio optimization; in other words, when utility is used explicitly. It can be shown that the normalization rule applied to $\mathrm{xi}^{*}$ that provides $\Sigma \mathrm{wi}^{*}=1$ embodies financial arbitrage, which is a critical component of the model. Arbitrage trading ensures that a portfolio can never be more valuable (in return-to-risk terms) than its constitutive parts, be they securities or other portfolios $-\mathrm{i}$.e, in $\mathrm{rp}=\mathrm{w}^{\prime} \mathrm{b}$, note that $\mathrm{rp} 1=\Sigma \mathrm{wi}^{*} \mathrm{ri}$ which, in turn, requires $1=\Sigma w i^{*}$, a linear rule. The optimization implies and requires the investor to be sensitive to both returns and risks, and it is optimizing in a market where those components are arbitraged effectively. There is no way to get additional returns in certain positions without bearing the additional, corresponding risk. The critical concept of market efficiency requires both investors and markets to play their parts each time an investment decision is made.

In Exhibit I, the lines beneath the variance-covariance matrix show optimal portfolio weights, and optimal portfolio figures. A portfolio of $m$ initial securities can be optimized in several ways, as explained in Tarrazo (2014). In early textbooks, it was explained as a solution to a simultaneous equation system, $\mathrm{A} x=\mathrm{b}$, where $\mathrm{A}$ is a m-by-m variance-covariance matrix, and $\mathrm{x}$ and $\mathrm{b}$ are $\mathrm{m}$-by-one vectors for the unknown optimal weights $\left(\mathrm{x}^{*}\right)$ and stock returns. These are the inputs appearing in the first block in Exhibit I. The solution $x^{*}=A-1 b$ gives a vector that may include negative values. Actual optimal weights are computed by dividing each $\mathrm{xi}^{*} / \operatorname{Sum}(\mathrm{xi} *)$, e.g., $1.64=11.23 / 6.83$, where 1.64 is $164 \%$. By the way, 6.83 is a very important number that happens to express both the return-to-risk ratio of the portfolio and that of each individual security ri/Ci. This is a consequence of linearity, see Tarrazo (2014).

Note that negative values for $\mathrm{xi}^{*}$ indicate the securities are sold short and, therefore, bring on financing that is used in the securities held "long". Eliminating short-sales, and drying their financing, is easy and can proceed in two ways: a) Basis Reduction Method: one can start with the whole set of stocks $m$ and sequentially eliminate the securities with negative weights, which took three optimizations as shown in the last block (left-hand side) in the Exhibit I; or b) Selective Basis Addition: Start with the two securities with the highest return-to-risk ratios (MCD and IBM) and go on adding one security at a time; keep the security if its optimal weight is positive, and rejects otherwise. This method took three optimizations, which are shown in the last in the last block (right-hand side) in Exhibit I. See Tarrazo (2014) for further detail. Normally, the analysis stops there but, carrying it a bit further we notice two additional items that are very important for the purposes of this study. First, note that the ranking of optimal portfolio weights follows the return-to-risk ranking of individual securities (shown to the right of optimal portfolio weights). Note also that the optimal, no short-sales (wi > 0), portfolio could have been calculated by any of the following sequential procedures:

a) "Basis reduction" (BR). Run the full-dimensional optimization and then successively eliminate those securities with negative weights.

b) "Selective basis addition" (SBA) procedure. Start with the two highest securities ranked in terms of their return-to-risk ratio (ri/stdi), and then we successively "try out" the rest of the securities having a positive return. If they receive a positive weight keep them in the optimization; otherwise, discard them forever and try the next security with a positive return. 
Exhibit I. Mean-Variance Optimization.

Variance-Covariance matrix (A), and returns vector (b):

\begin{tabular}{|c|c|c|c|c|c|c|c|}
\hline & $M C D$ & IBM & $H P Q$ & $K O$ & PFE & $G E$ & Returns \\
\hline MCD & 0.002337 & 0.000917 & 0.001509 & 0.001356 & 0.001494 & 0.002187 & 0.016911 \\
\hline IBM & 000917 & 0.003591 & 0.002336 & 0.001217 & 0.000315 & 0.002359 & 801 \\
\hline HPQ & 001509 & 0.002336 & 0.004872 & 0.001488 & 0.001697 & 0.003797 & 0.0 \\
\hline KO & 001 & 0.001217 & 0.001488 & 0.00241 & 0.001117 & 0.002856 & 0.005473 \\
\hline PFE & 001494 & 0.000315 & 0.001697 & 0.001117 & 0.004184 & 0.003008 & -0.00709 \\
\hline GE & 0.002187 & 0.002359 & 0.003797 & 0.002856 & 0.003008 & 0.010211 & -0.01148 \\
\hline
\end{tabular}

Optimal results, short sales $(w i<0)$ allowed $\mathrm{A} x=\mathrm{b}, \mathrm{x}^{*}=\mathrm{A}-1 \mathrm{~b}$ :

\begin{tabular}{|c|c|c|c|c|}
\hline & $x$ & $w$ & ri/stdi & $\mathrm{ri} / \mathrm{Ci}=1 / \lambda 1$ \\
\hline MCD & 11.23754 & 1.644735 & 0.349792 & 6.832433 \\
\hline IBM & 0.833271 & 0.121958 & 0.163552 & 6.832433 \\
\hline HPQ & 2.487044 & 0.364006 & 0.155465 & 6.832433 \\
\hline KO & -0.00273 & -0.0004 & 0.111483 & 6.832433 \\
\hline PFE & -4.36001 & -0.63813 & -0.1096 & 6.832433 \\
\hline GE & -3.36268 & -0.49216 & -0.11358 & 6.832433 \\
\hline Sum & 6.832433 & 1 & & \\
\hline
\end{tabular}

Alternative sequential approaches to find the optimal, no short-sales (wi > 0), portfolio:

\begin{tabular}{|l|r|r|l|l|l|r|}
\cline { 2 - 7 } & \multicolumn{3}{|l|}{ Basis reduction (BR) } & & \multicolumn{3}{|l|}{ Selective basis addition (SBA) } \\
\hline MCD & Opt 1 & Opt 2 & Opt 3 & Opt 1 & Opt 2 & Opt 3 \\
\cline { 2 - 8 } & 1.644735 & 0.910016 & 0.874922 & 0.874922 & 0.910016 & 1.247012 \\
\hline IBM & 0.121958 & 0.166776 & 0.125078 & 0.125078 & 0.166776 & 0.248015 \\
\hline HPQ & 0.364006 & -0.07679 & & & -0.07679 & \\
\hline KO & -0.0004 & & & & & -0.49503 \\
\hline PFE & -0.63813 & & & & & \\
\hline GE & -0.49216 & & & & & 1 \\
\hline Sum & 1 & 1 & 1 & 1 & 1 & 1 \\
\hline rp & 0.043129 & 0.01619 & 0.016021 & 0.016021 & 0.01619 & 0.020809 \\
\hline pvar & 0.006312 & 0.002072 & 0.002046 & 0.002046 & 0.002072 & 0.00304 \\
\hline pstd & 0.079451 & 0.045517 & 0.045233 & 0.045233 & 0.045517 & 0.055139 \\
\hline rp/pstd & 0.542843 & 0.355695 & 0.354195 & 0.354195 & 0.355695 & 0.377394 \\
\hline rp/pvar & 6.832443 & 7.814468 & 7.830387 & 7.830387 & 7.814468 & 6.84438 \\
\hline
\end{tabular}

These results reveal two important findings highlighting the capacity of linear heuristics and that of the return-to-risk heuristic in particular.

1) When the portfolio as a whole has a positive return, securities with negative returns cannot be part of that portfolio. At the optimal, each security has the same contribution to the optimal portfolio. In other words, the ratio of marginal returns-to-marginal variance is the same for each security. This ratio of marginal values is represented by $\mathrm{ri} / \mathrm{ci}$, where $\mathrm{ci}=\mathrm{Ai} \mathrm{w}^{*}$, and $\mathrm{Ai}$ is the row corresponding to the "ith" security in the variance covariance matrix A. B. This is known in demand theory in microeconomics as the equality of weighted marginal utilities (i.e., price-to-marginal utilities). Because of linearity, this is also the return-to-risk ratio for the portfolio as a whole. In our data, $6.832433=\mathrm{ri} / \mathrm{Ci}=\mathrm{rp} / \mathrm{pvar}$, and this ratio would also be related to the value of the Lagrangian multiplier, $1 / \lambda 1$, had we used that particular optimization procedure. The insight is that, as long the portfolio return is positive (its variance will always be positive for a non-trivial portfolio), only securities with positive returns will be considered for inclusion in the optimal portfolio. (What about the case of having a negative portfolio return? -Save your money and effort, and don't invest.) 
2) Note the power of the return-to-risk heuristic, according to which the data was ranked and allows such a clear appreciation of which securities will come at the top, the most valuable investments under the mean-variance criterion.

And these two findings, in turn, hint at the two major pay-offs of the effort made up to this point. The first one concerns the power of linear heuristics in portfolio optimization, which substantiates Barone-Adessi's confidence in these constructs. Note that, in general, the term "heuristic" is often used in the sense of an approximation. However, the return-to-risk heuristic is sometimes powerful enough to identify optimal securities in mean-variance analysis. Another potential linear heuristic, ri $>0$, is a necessary but not sufficient condition for observing a positive weight, as is the case with the securities HPQ and KO. In the example presented in Exhibit I, the return-to-risk heuristic (ri/stdi) was able to anticipate exactly the qualitative ranking in the optimization. These effects can also be observed in larger samples, as we will show in the next section.

The second pay-off from the analysis presented in this section has a major scope. A qualitative portfolio model could be constructed by following the characteristics of mean-variance analysis. First, one would identify an indicator reflecting a key characteristic sought after for each of the objects of choice. This indicator should be positive, the larger value reflecting a better choice. The collection of values for each indicator would form a vector playing the role of $b$. The entries of the matrix A could be made up by the range of this particular indicator for each of the objects of choice (main diagonal), and how the range of each indicator affects the range's other indicators (off-diagonal elements). As noted earlier, the entries on the vector $\mathrm{b}$ should be strictly positive, and the entries in A should be such that A is positive definite (every major determinant positive). A better way to state the requirements for $\mathrm{A}$ and $\mathrm{b}$, is that $\mathrm{A}$ should be quasi-diagonally dominant, which means that one can find optimal weights for which $\mathrm{A} w$ is diagonally dominant. It is well-known that when securities are not related, covariance terms (off-diagonal elements in A) equal zero, and the optimal weights are simply a weighted average of the linear return-to-risk heuristic: wi* $=$ ri/vari $/($ ri $/$ vari). Quasi-diagonal dominance allows the linear risk-to-return heuristic to suffice to establish its rank in the optimal solution without being thwarted by covariance-effects. In other words, the optimization is ultimately dictated by the linear heuristic bi/aii.

This section has presented material from several of the areas tributary to portfolio optimization (finance, optimization, and linear algebra). For further detail, the reader is referred to Tarrazo (2014) which focuses on the properties of the optimization, and also Tarrazo (2009), which studies the power of the heuristic ri/stdi to anticipate and enhance portfolio optimization, and where detail concerning the selective basis addition algorithm and other sequential procedures can be found. The relationship between positive returns and positive portfolio weights is analyzed in Tarrazo (2008a), and exploited in subsequent studies by this author (2012, 2009), and Tarrazo and Ubeda (2012).

\section{Qualitatively Different Portfolios and Development of Heuristics}

In this section, we will complement the material presented in three ways: first, by further exploring valid portfolio optimizations beyond that of the "tangent" portfolio; second, by suggesting some ways that may result in more useful heuristics; and, third, by commenting on actual portfolio optimization results.

\subsection{Qualitative Differences Along the Efficient Frontier}

In the previous section, we focused on a portfolio with special characteristics: the portfolio that has the highest return-to-risk ratio (rp/pvar). It implements arbitrage; it is not dominated by any other portfolio, and it can be shown to have optimal predictor properties, Tarrazo (2014). Notwithstanding, since the beginning of portfolio optimization, researchers have studied other valid portfolios which investors could consider. These are portfolios that are not "dominated" by other portfolios -no other portfolio has better returns with equal or lower risks, or lower risk for the same level of returns. These portfolios form the so-called "efficient frontier", which ranges from the portfolio with minimum variance to that with maximum return.

Exhibit II shows optimal weights and portfolio figures for the efficient frontier using the example from the previous section. The portfolio with the minimum variance is $\mathrm{p} 1$. The portfolio with the maximum return, and also the maximum variance, is p6. The portfolio maximizing the return-to-risk portfolio is found between these two "extreme" portfolios. Exhibit III depicts the evolution of optimal weights as we transition from $\mathrm{p} 1$ towards p6 (it makes more sense to transition from $\mathrm{p} 6$ to $\mathrm{p} 1$ ). A key effect is that the number of securities also varies as we create higher return-to-risk portfolios. In other words, qualitatively better portfolios include less securities but of a higher quality (higher individual return-to-risk), given the portfolio optimization values. Furthermore, the quality quickly downgrades as we move downwards to the minimum variance portfolio. This yields a key insight: qualitatively, the minimum variance portfolio may not be the minimum risk portfolio. At this point, we have reached the theoretical nucleus where the practical import of portfolio theory resides: the best portfolio should be one that maximizes the return-to-variance portfolio (p5, rp/pvar $=8.038518$ ), while having enough securities to offer diversification, but without adding securities of a lower quality. 
The reader may also have anticipated the next two critical questions: 1) how many securities make up a diversified portfolio? And, 2) can portfolio theory be implemented?

The answer to the first question ranges from 15 securities to 100 securities as the minimum required; statisticians and hedgers argue for the larger number on the bases of statistical reliability of estimates, or on the basis of better risk management, respectively. But the investor interested benefiting from portfolio theory may also face limitations concerning the investing budget, which is the case of small (household) investors. For example, placing about $\$ 20,000$ in 15 securities would amount to a minimum of funds of about $\$ 300,000$. Responding to the second question requires a look at actual investing-grade optimizations, which we shall do next.

\subsection{Actual Investment Optimizations}

One way to facilitate finding optimal positions is to make sure one has not only enough securities to find diversifying behavior (not all securities going up or down at the same time), but also that they are economically different (different sizes, different growth patterns, different industry, markets, and sectors, and so on). The reader may have noted we are handling suddenly qualitative matters. We have to do so because, unfortunately, the numbers are insufficient to guide optimal investing behavior.

Exhibit IV presents portfolio optimizations for the stocks of the "Dow Jones Industrial Average" (DJIA) for three different periods, which includes 30 securities. Another recommended "hunting ground" for securities is the "Standard \& Poor's 500 Industrial Average" (S\&P500), which includes 500 securities. However, the correlation between these indices is very high -e.g., it reached $98.18 \%$ for the 6/1/2010-5/31/2005 period. Furthermore, the DJIA attracts a great deal of attention for investors because it is easier to follow 30 than 500 companies, see for example Siegel (2005). In addition, as noted earlier. We must also consider that individual investors have a limited number of funds to invest, which reduces the number of different positions they can have.

When we try to apply portfolio theory to actual data we notice at least the following points:

a) The optimization is very influenced by the sample period. We have followed an unwritten rule of five years-worth of monthly data, but there is little guidance beyond this, see Fabozzi, Gupta, and Markowitz (2002).

b) The optimal tangent portfolio may not promise much diversification. For instance, the "1998-2003" and the "2005-2010" optimization yield tangent portfolios of only two securities. The "2003-2008" period optimization appears much more promising in providing some diversification but, on closer inspection, we see that four stocks command nearly $60 \%$ of the investing funds (58.3\% exactly, on MCD, JNJ, CVX, and BA).

c) The horizontal line in each of the three blocks divides those stocks with a positive average return and those with a negative one. We can appreciate how many securities with positive returns are not included in the optimal (tangent) solution, which seems to exhibit "winner takes it all" lopsided proportions. This means that a heuristic of simply "accumulating securities with positive returns" may not help much.

d) Very importantly, we do observe the power of the individual return-to-risk heuristic to rank-predict optimal positions. The rule-of-thumb of investing in the top five securities in terms of their "ri/stdi" gets the $67.34 \%$ top accumulated portfolio weights in the "2003-2008" and the $100 \%$ in the other two periods. (By the way, the heuristic return-to-variance, ri/vari, is the appropriate one to use for both individual securities and portfolios.) 
Exhibit II. Efficient Frontier.

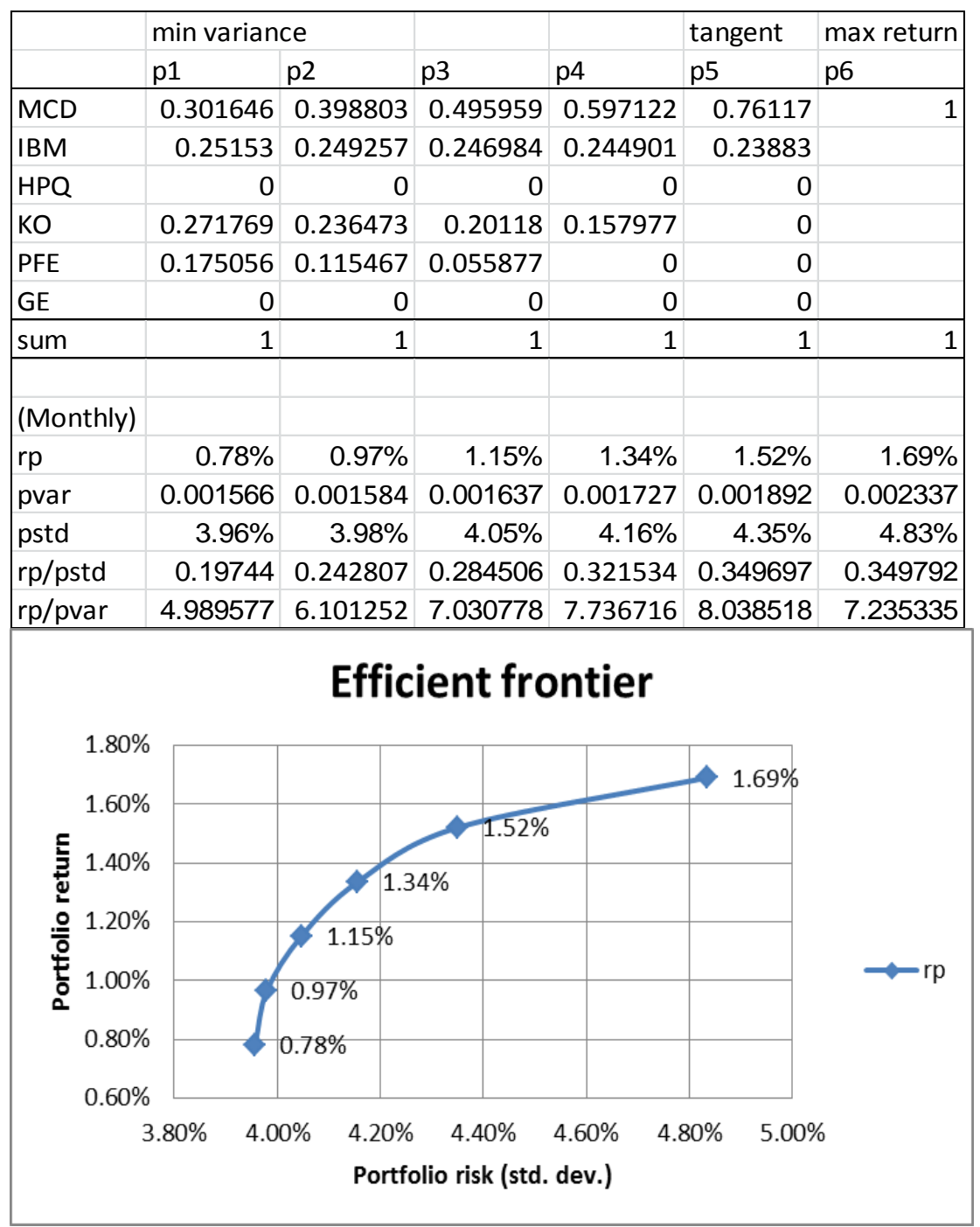

Inspection of optimizations with potential actual investing values reveals that the individual return-to-risk heuristics does summarize and carry much of the theoretical content of portfolio optimization. But it also needs to be complemented with qualitative analysis - perhaps other linear, qualitative heuristics-- to enhance practical application of the theory. Our analysis, however, does provide some note of caution on how to get started in this respect.

\subsection{A Note of Caution on the Construction of Heuristics}

It is clear that portfolio theory does not offer a clear, identifiable set of rules to follow. Much critical detail in its implementation is left to the investor (sample selection, number of securities, frequency, and so on.) It seems prudent to try to build on the most solid foundations available, or else we risk not being able to explain results. Our analysis suggests building upon the following three items: 1) the tangent portfolio, 2) the individual return-to-risk heuristic, and 3 ) in the context of a number of securities small enough for the investor to be able to evaluate the resulting optimal portfolio weight in terms of economic and company fundamentals. 
Exhibit III. Securities and Qualitative Effects
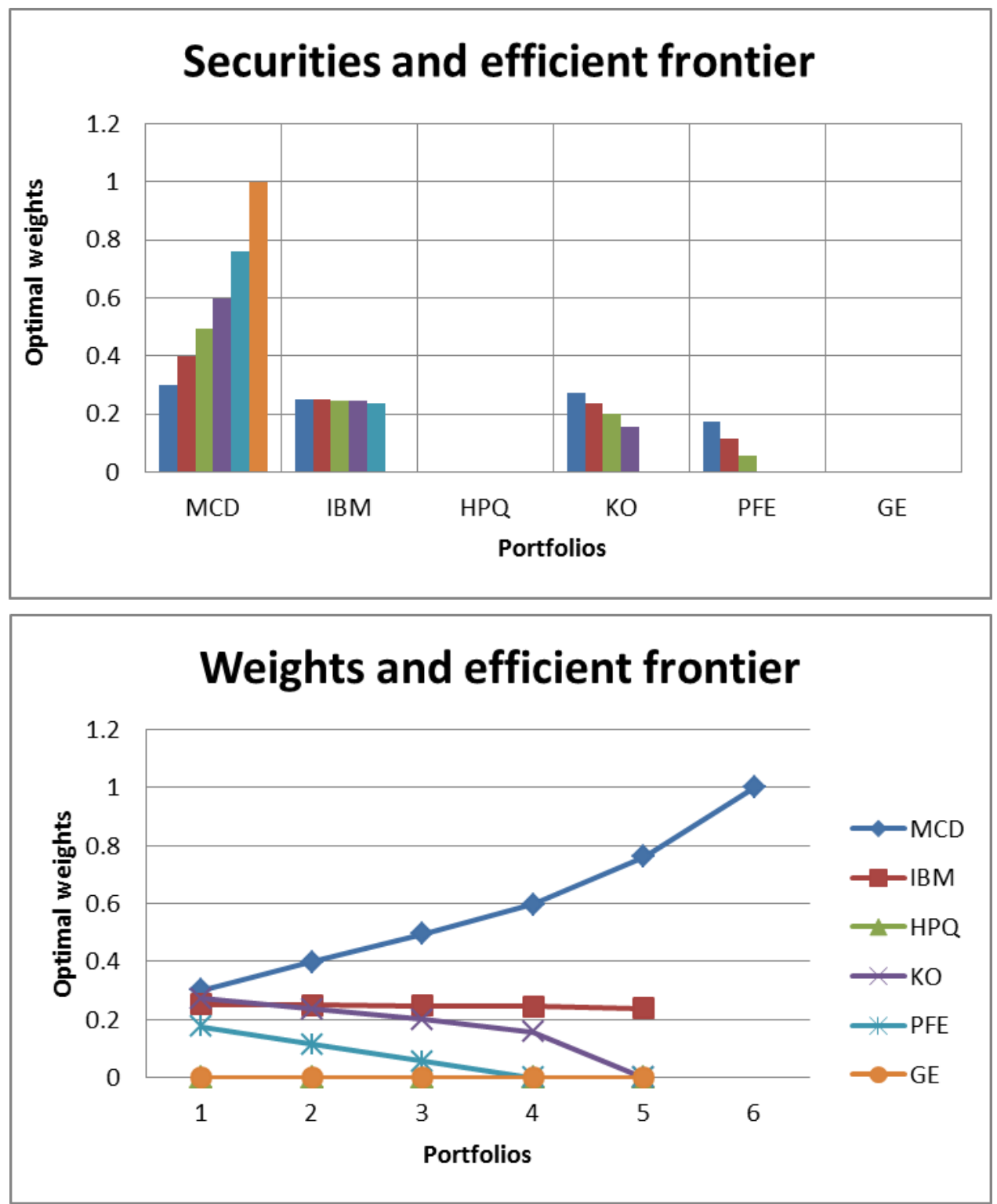

In the literature, many results have been calculated in ways that may raise more questions than they solve:

1) Using samples containing hundreds (and hundreds) of securities. What fundamental follow-up can you apply to evaluate the quality of portfolio weights? What type of investor would spread their funds in such a way?

2) Calculating non-optimal portfolios. For example, portfolios where securities are assigned equal proportions have attracted many researchers. In this case, however, unless some initial criteria to select the securities has been implemented, it seems the analyst is simply throwing away not only what the individual return-to-risk heuristic has to offer, but also the value of numerical optimization,.

3) Applying non-standard computations, in some cases authors replace actual, observed values with artificial ones generated by, for example, simulation. This is equivalent to replacing market-made uncertainty with one man-made.

4) Focusing on the minimum variance portfolio instead of the tangent portfolio. As we have shown, the minimum-variance portfolio is qualitatively the worst of all acceptable portfolios. It is not an optimal predictor because it neglects returns (one only optimizes the quadratic form $G(x)=-1 / 2 x$ ' $A x$, when minimizing the variance of the portfolio). 
Exhibit IV. Optimizations, Dow-Jones Industrials Average.

\begin{tabular}{|c|c|c|c|c|c|c|c|c|c|}
\hline & \multicolumn{3}{|c|}{$6 / 1 / 2010-5 / 31 / 2005$} & \multicolumn{3}{|c|}{$4 / 1 / 2008-3 / 31 / 2003$} & \multicolumn{3}{|c|}{$11 / 3 / 2003-12 / 01 / 1998$} \\
\hline & & sorted & NSS & & sorted & NSS & & sorted & NSS \\
\hline & Ticker & ri/stdi & tangent & Ticker & ri/stdi & tangent & Ticker & ri/stdi & tangent \\
\hline 1 & MCD & 0.349792 & 0.874922 & MCD & 0.422509 & 0.203917 & MMM & 0.261209 & 0.820107 \\
\hline 2 & IBM & 0.163552 & 0.125078 & UTX & 0.379721 & 0.084 & C & 0.154224 & 0.160004 \\
\hline 3 & HPQ & 0.155465 & & CVX & 0.37362 & 0.116184 & CAT & 0.106454 & 0 \\
\hline 4 & KO & 0.111483 & & XOM & 0.32892 & 0.011961 & UTX & 0.096706 & 0 \\
\hline 5 & TRV & 0.105293 & & CAT & 0.322833 & 0.086492 & $A A$ & 0.095815 & 0 \\
\hline 6 & CVX & 0.09833 & & BA & 0.317197 & 0.112493 & AXP & 0.074469 & 0 \\
\hline 7 & UTX & 0.095426 & & $\mathrm{HPQ}$ & 0.287006 & 0 & WMT & 0.068275 & 0.002498 \\
\hline 8 & PG & 0.084841 & & $\mathbf{T}$ & 0.256979 & 0.048972 & $\mathrm{JNJ}$ & 0.063278 & 0 \\
\hline 9 & $\mathrm{~T}$ & 0.077528 & & PG & 0.241008 & 0.02235 & XOM & 0.055344 & 0 \\
\hline 10 & MRK & 0.072305 & & KO & 0.210102 & 0 & BA & 0.038652 & 0 \\
\hline 11 & DIS & 0.067789 & & JPM & 0.204281 & 0.055069 & MO & 0.036374 & 0 \\
\hline 12 & MMM & 0.058056 & & DIS & 0.190007 & 0 & PG & 0.031413 & 0.017391 \\
\hline 13 & CAT & 0.051682 & & GE & 0.17703 & 0 & HPQ & 0.020182 & 0 \\
\hline 14 & JPM & 0.030403 & & AXP & 0.146239 & 0 & INTC & 0.014146 & 0 \\
\hline 15 & WMT & 0.029817 & & JNJ & 0.135872 & 0.150697 & IBM & 0.002148 & 0 \\
\hline 16 & XOM & 0.029685 & & BAC & 0.131659 & 0.01768 & IP & -0.00982 & \\
\hline 17 & VZ & 0.026016 & & $A A$ & 0.129226 & 0 & GE & -0.01169 & \\
\hline 18 & CSCO & 0.022831 & & IBM & 0.122984 & 0 & HD & -0.01277 & \\
\hline 19 & JNJ & 0.016389 & & MMM & 0.116577 & 0 & DD & -0.02044 & \\
\hline 20 & KFT & 0.014402 & & DD & 0.095524 & 0 & GM & -0.02099 & \\
\hline 21 & BA & 0.011325 & & VZ & 0.083618 & 0 & MSFT & -0.0364 & \\
\hline 22 & MSFT & 0.001698 & & MSFT & 0.082953 & 0 & HON & -0.03644 & \\
\hline 23 & DD & -0.00291 & & INTC & 0.050069 & 0 & JPM & -0.03657 & \\
\hline 24 & AXP & -0.00955 & & HD & 0.032792 & 0 & DIS & -0.03945 & \\
\hline 25 & INTC & -0.03481 & & WMT & 0.009282 & 0.090185 & KO & -0.06381 & \\
\hline 26 & $H D$ & -0.04247 & & MRK & -0.03431 & 0 & MCD & -0.06783 & \\
\hline 27 & BAC & -0.08715 & & AIG & -0.04532 & 0 & MRK & -0.08187 & \\
\hline 28 & AA & -0.09757 & & GM & -0.05196 & 0 & SBC & -0.10922 & \\
\hline 29 & PFE & -0.1096 & & PFE & -0.06166 & 0 & EK & -0.12969 & \\
\hline 30 & GE & -0.11358 & & C & -0.08424 & 0 & $\mathrm{~T}$ & -0.26613 & \\
\hline \multirow[t]{5}{*}{ monthly } & $\mathrm{rp}$ & & 0.016021 & & & 0.014226 & & & 0.016352 \\
\hline & pvar & & 0.002046 & & & 0.000575 & & & 0.003744 \\
\hline & pstd & & 0.045233 & & & 0.023975 & & & 0.061189 \\
\hline & rp/pstd & & 0.354195 & & & 0.593362 & & & 0.267228 \\
\hline & $\mathrm{rp} / \mathrm{pvar}$ & & 7.830387 & & & 24.74924 & & & 4.367219 \\
\hline \multicolumn{10}{|l|}{ yearly } \\
\hline & $\mathrm{rp}$ & & $19.23 \%$ & & & $17.07 \%$ & & & $19.62 \%$ \\
\hline & pvar & & 0.024553 & & & 0.006898 & & & 0.04493 \\
\hline & pstd & & $15.67 \%$ & & & $8.31 \%$ & & & $21.20 \%$ \\
\hline & $\mathrm{rp} / \mathrm{pstd}$ & & 1.226968 & & & 2.055466 & & & 0.925704 \\
\hline & $\mathrm{rp} / \mathrm{pvar}$ & & 7.830387 & & & 24.74924 & & & 4.367219 \\
\hline mdeterm & & $1.38 \mathrm{E}-82$ & 7.55E-06 & & $-2.44 \mathrm{E}-85$ & $1.80 \mathrm{E}-34$ & & $9.31 \mathrm{E}-71$ & $1.06 \mathrm{E}-09$ \\
\hline \multicolumn{2}{|c|}{ emax $=\operatorname{norm}(k)$} & 0.1072 & 0.0041 & & 0.0242 & 0.0087 & & 0.108146 & 0.01127 \\
\hline emin & & 0.000165 & 0.001864 & & $5.16 \mathrm{E}-05$ & 0.00035 & & 0.000401 & 0.002958 \\
\hline \multicolumn{2}{|c|}{$\operatorname{cond}(k)=$ emax $/$ emin } & 651.6525 & 2.1991 & & 469.2584 & 24.8673 & & 269.7937 & 3.809661 \\
\hline
\end{tabular}

Unfortunately, it is not uncommon to find cases where the concurrence of all 1-4 instances make the corresponding results hard to assess, as studied in Tarrazo and Ubeda (2012).

Two other notes of caution related to single-index models, especially when the optimization carries crippling assumptions. Single index models compute optimal security weights by first computing their regression numbers again an index. The theoretical support comes from what is known as the Capital Asset Pricing Model, see Barone-Adesi (2007). It should be clear that using an index extracted from the sample data would provide exactly mean-variance 
weights, and that only an index bringing outside-the sample information would provide different weights. It turns out that the index usually used is the S\&P500, but it is always unclear how it is related to what the sample is, or should be. Therefore, there is a school of thought (Roll's Critique), that argues that the contribution of the single index model to portfolio theory is untestable because its evaluation amounts to a joint-test of both mean-variance and the efficiency of the index itself. In addition, the initial regressions of the index on the securities to get the initial betas ignores the error-covariance structure $\left(\sigma \mathrm{e}_{\mathrm{ij}}, \mathrm{i} \neq \mathrm{j}\right)$, only recognizing the individual security variance and its covariance with the market. The intention may be good (highlight the relation of the security with the index), but the action is still entirely arbitrary. The problems compound when multi-index models are contemplated.

In sum, we believe the best way to set out to enhance portfolio theory is to focus on mean-variance analysis in the three aforementioned cases -tangent portfolio, individual return-to risk heuristic, and a reduced number of securities (perhaps no more than 30).

\section{Further Detail and Promising Perspectives}

In this section we want to extend the analysis presented thus far to point out promising perspectives in enhancing portfolio selection with qualitative analysis. We will briefly comment on three of such perspectives, which we will organize in terms of comprehensiveness, reach, and scope.

\subsection{Linear, Qualitative-But-Measurable Heuristics}

Research on these is already at the implementation stage, and there are mutual funds and exchange-traded funds offering investing strategies built with fundamental analysis heuristics. These heuristics try to sidestep the vagaries of stock-market numbers and link the quality of the stock to the quality of the company which, in turn, is linked to key economic or company data; see for example, Arnott, Hu, and West (2008). According to our analysis, this effort should also benefit from being applied to exchange-traded-funds, which, invest in a reduced number of securities (40-60) compared to mutual funds.

\subsection{Portfolio Metaheuristics}

The mean-variance model does not include critical factors that go beyond the statistics-plus-numerical-optimization procedures described in the first section. When we try to help specific investors, or even to improve upon the model, we need to proceed via qualitative methods. Di Tollo and Roli (2008) suggest using "metaheuristics", which are ways to widen the conceptualization of each item in the original model (variables, objectives, constraints) to enhance the model -i.e., more robust, wider applicability, more practical. These authors understand "metaheuristics" as strategies based on approximate algorithms applied in problems needing combinatorial optimization and which, otherwise, would be unsolvable. Metaheuristics, for example, could help investors to decide when to exit the stock market (sell partially or completely) their portfolios. Martellini and Urosevic (2006) show that the static mean-variance model may not provide the best portfolios when the investor faces uncertain time-horizons. Portfolio theory says little about optimal revision policies -a related problem to timing investment exits.

\subsection{Decision Heuristics}

To the "technical" component of investing one must add the "human" component. Investors, and especially small investors, have to deal with many decision making challenges because they have limited budgets, alternative uses for those funds, and limited knowledge. Simon (1955) completed early pioneering work in heuristic problem solving particularly as it related to operations research. Tversky and Kahneman (1974) further explicated heuristic models to an individual dimension, defining them as simplifying mechanisms for complex decisions. Shrivastava and Lim (1984) and Stubbart and Ramaprasad (1990) focus on identifying simplifications and biases in executives' maps of their industries. Individual biases are a product of each decision maker's cognitive structure. Cognitive structures are necessary to prevent decision makers from becoming paralyzed by the need to analyze extensive data (Weick, 1979; Hogarth, 1980; Daft and Weick, 1984). Further, Janis (1989) asserts decision makers often take shortcuts. One of these relates to simple decision rules -- relying on existing procedures or a well-known analogy. These analogies may, of course, be based on comfortable heuristics that may be identified by predominant metaphor usage. These shortcuts limit the comprehensiveness of the decision process. Janis' notion of simple decision rules and incrementation support the notion of the influence of heuristics in decision making which may be partly responsible for the nature and quality of decision making.

The investing problem is one of the most complex ones faced by individuals in our modern societies, thus, often leading to the conscious or unconscious development of decision heuristics. In addition to security selection, it is related to many other critical decisions such as health, health care, housing, care for dependents, retirement preparation and management, and so on. The problem is also overwhelming for even finance professors, as noted sharply by Doran and Wright (2010), among others. Herbert Simon (see 1955, for example) noted that decision makers were likely to find it difficult to use some models that, nonetheless, appear very reasonable in textbooks and theoretical research. Simon 
argued for a "bounded rationality" approach that was, not only more realistic but also better suited to computer processing. Some of the research spawned from Simon's work focuses solely on the many ways in which people err when making decisions. More constructively, other research strands try to ascertain how to help decision makers by recognizing the "fast and frugal" way by which individuals try to adapt to an increasingly more difficult environment (more information to process, more choices that are more difficult to evaluate, more to lose, and so on); see, for instance, Gigerenzer (2000, p. 166 and ss., 2001, and 1999), and Baker and Nofsinger (2002).

Exhibit V. Suitability, Characteristics, and Relational Equations

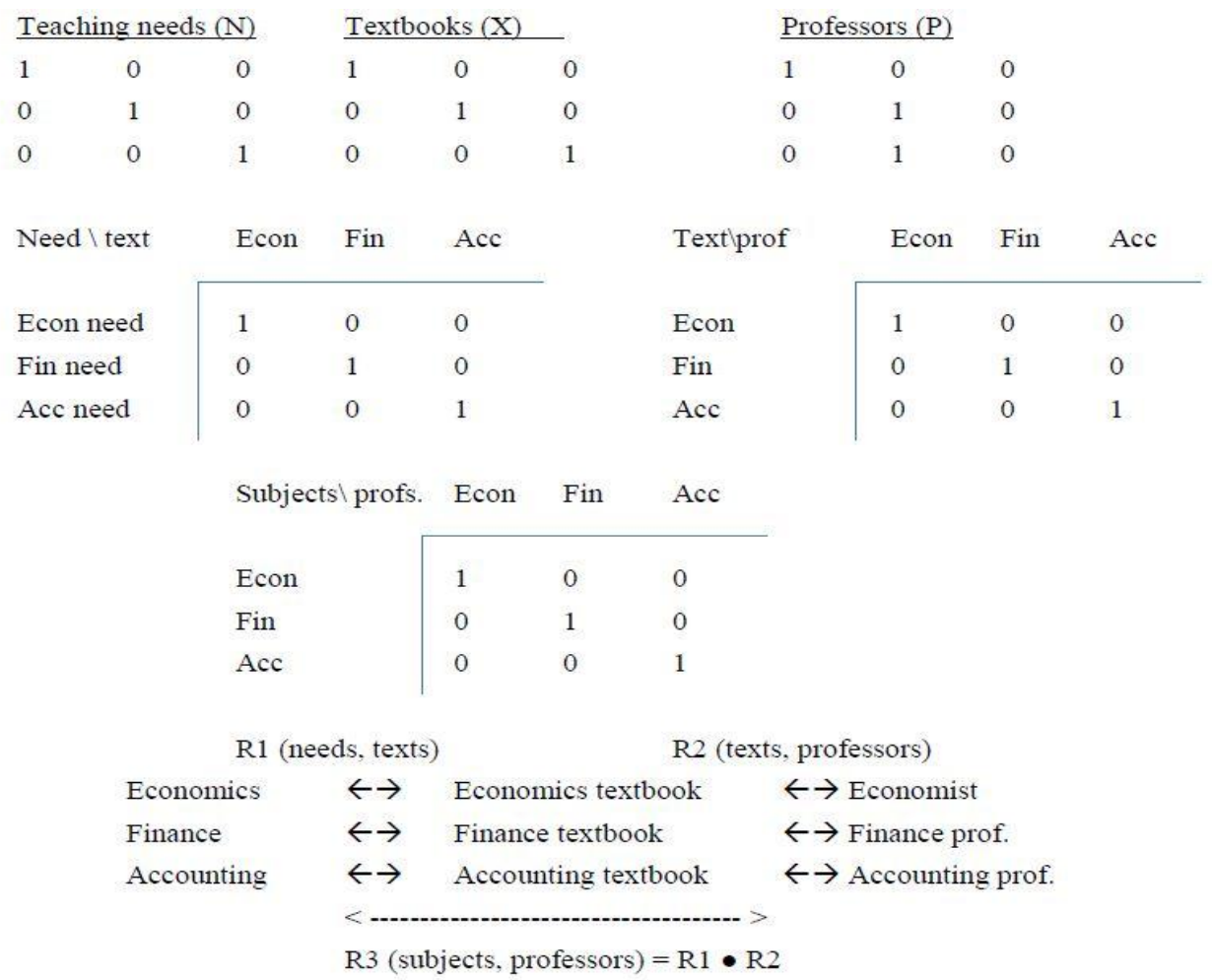

\subsection{Relational Equations}

Exhibit V illustrates how this approach operates. Suppose there are three subjects to be taught (economics, finance, accounting), three textbooks available (economics, finance, accounting), and three potential professors (economist, finance, and accounting). Obviously, as the problem is described, it seems best to relate each one of the elements in each set in the order they appear within the brackets. Notice now matrixes can be used to represent the items (elements) of each of these three groupings (sets). Multiplying matrices $\mathrm{N} * \mathrm{~T}$, we would have a matrix NX representing the first relation, $\mathrm{NX}=\mathrm{R} 1$ (needs, texts). Multiplying $\mathrm{X} * \mathrm{P}$, we would have a matrix representing the second relationship of interest, $\mathrm{XP}=\mathrm{R} 2$ (texts, professors). Multiplying $\mathrm{NX} * \mathrm{XP}$ we would have a matrix relating subjects to be taught directly to professors, $\mathrm{NP}=\mathrm{NX} * \mathrm{XP}$, capturing the third relationship of interest $\mathrm{R} 3$ (subjects, professors). Identity matrices represent the simplest case imaginable in assignment problems (perfect matching). Matters get more interesting when subjects do not perfectly match teaching materials or available faculty. For example, consider interdisciplinary subjects (financial economics, personal financial planning), or whether some faculty can teach more than one subject, or whether the teaching materials overlap. These cases would be represented by the off-diagonal elements in each of the matrices. The analysis is very flexible, and the entries can also reflect negative values (negative student reactions to a professor teaching outside his/her area of expertise). Furthermore, the analysis can be applied to the "demand for characteristics" case, in which consumer's ultimate goals are certain characteristics, totally or partially present in the intermediate goods purchased Lancaster (1966). Smith (1974) applies suitability analysis to household financial planning. In this case the groupings are Age groups $=\{25,35,45,55,65\}$, Characteristics $=\{$ liquidity, income, appreciation, safety $\}$, and Assets $=$ \{savings account, corporate bonds, stocks, real estate $\}$. The corresponding multiplication matrices would be as follows: M1 = (age groups, security characteristics), M2 = (characteristics, assets), and $\mathrm{M} 3=\mathrm{M} 1 * \mathrm{M} 2$, which would indicate the asset portfolio mix for each group.

Tarrazo $(1999,1997)$ reformulated Smith's (1974) analysis using the methodology of fuzzy sets and, more specifically applying it as a relational-equations-possibilistic model (REP). This methodology has been developed to process concepts whose adequacy/possibility are a matter of degree. In some cases, a deviation from a given amount may not 
matter much because the sets and elements need not be as precise as in calculus. The key relationships are specified at the level of "sets" not "variables": R1= (age groups, security characteristics), R2 = (characteristics, assets), and R3 = M1 • M2, where the operator "•" represents a logical rule (maxi-min, for example) rather than an arithmetic rule. The end result is a set of coefficients capturing both qualitative relationships and quantitative intensity, and yet maintaining the linear framework of conventional portfolio models. This methodology makes information exchanges very efficient, and it is easy to modify to include different aspects of the decision. It is also very well suited to integrate "expert" assessments. REP and other (granular computing) tools to integrate qualitative and quantitative information making use of intervals, which for Tarrazo (2008) can be taken as the bridge between words and numbers and the language of strategy. (The qualitative side of this bridge may include work such as Cannice and Bell (2010) which examined the use of metaphors by venture capitalists. From a systematic collection and classification of venture capitalists' utterances of metaphor which acted as unconscious 'tells', the study authors constructed a typology of VC decision maker types ranging from a Darwinist whose frame of reference is that 'only the strongest will survive' to the Priest - who looks for 'meaning in new ventures'.)

In sum, these four approaches all aim at enhancing quantitatively-based decision making with qualitative elements. Nofsinger (2011), for example, concludes that the ways to avoid investing decision-making errors by behavioral/cognitive biases are the following: 1) understand the biases, 2) know why you are investing, 3) have quantitative investment criteria, 4) diversify, and 5) control your investment environment. The disappointments, frustration, thoughts of what might have been, and regrets, which are also part of investing may only be addressed with qualitative knowledge, see Acker (1997).

From time to time there are areas of science that benefit enormously from a focus on certain problems. That seems to have been the case with the fruit fly in biological research, and with chess in artificial intelligence. It seems plausible that further research integrating qualitative and quantitative elements could enable portfolio selection to play a similar role in the advancement of investing, in particular, and of decision making in general.

\section{Concluding Comments and Areas of Further Research}

This study set out to contribute to what we believe to be a very advantageous way to enhance portfolio selection -its implicit linear heuristics. We did so by clarifying, complementing, and extending a timely contribution in this effort.

We first clarified how portfolio optimization works, and the role played by a critical linear heuristic --the individual return-to-risk ratio. Then, we proposed a very straightforward way to build qualitative analogs to the standard, quantitative-only, mean-variance portfolio optimization -that is, by replicating its numeric properties with qualitative indicators. Then afterwards, we focused on the qualitative elements already present in portfolio choice that, nonetheless, are overlooked in the current, quantitative-only approaches. Because of quality issues, the minimum-variance portfolio is most likely not to be the minimum-risk one. We also noted that some approaches to implementing portfolio heuristics may be more productive than others. Specifically, we advocated for adding qualitative elements to the clearest and more transparent implementations of the theory -tangent portfolios in mean-variance analysis, calculated in the most standard way, and applied to rather small portfolios. In the last section we surveyed and explored additional ways in which portfolio selection can be enhanced with qualitative elements.

In general, qualitative-quantitative integrations are needed in situations where information is most scarce (e.g., venture capital, initial public offerings); in forward-looking decisions, where all that matters is set in the uncertain future (e.g., retirement planning); and in decisions where strategy, which normally requires the integration of words and numbers, is the key. We also contend that portfolio heuristics may be exposed unconsciously through metaphorical tells that individuals and managers may use. We expect an exploration into the metaphorical tells of portfolio heuristics may be a fruitful area of further investigation. These days it seems investing is no longer possible without using qualitative guidance. Perhaps it never was possible. The difference is that nowadays, as indicated in this study, we have the tools, models, and methodologies to benefit from qualitative information and reasoning.

\section{References}

Acker, M. (1997). Tempered Regrets under Total Ignorance. Theory-and-Decision, 42(3), 207-13. http://dx.doi.org/10.1023/a:1004907110913

Arnott, R., Hu, J., \& West, J. (2008). The Fundamental Index: A Better Way to Invest. Hoboken, New Jersey: John Wiley \& Sons, Inc. http://dx.doi.org/10.1007/s11408-008-0084-8

Baker, H. K., \& Nofsinger, J. (2002). Psychological Biases of Investors. Financial Services Review, 11, 97-116. http://dx.doi.org/10.1023/a:1022889315782

Barone-Adesi, G. (2007). Linear Portfolio Weights. Quantitative and Qualitative Analysis in Social Sciences, 1(2), $25-32$. 
Cannice, M., \& Bell, A. (2010). Metaphors Used by Venture Capitalists: Darwinism, Architecture, and Myth, Venture Capital: An International Journal of Entrepreneurial Finance, 12(1), 1-20. http://dx.doi.org/10.1080/13691060903184787

Constantinides, G., \& Malliaris, A. (1995). Portfolio Theory, in Jarrow, R., Maksimovic, V., and W. Ziemba, eds.: Handbook in OR \& MS, 9(1), 1-30. Amsterdam, The Netherlands: Elsevier Science, B.V. http://dx.doi.org/10.1016/s0927-0507(05)80045-3

Daft, R. L., \& Weick, K. E. (1984). Toward a Model of Organizations as Interpretation Systems. Academy of Management Review, 9, 284 - 295. http://dx.doi.org/10.5465/amr.1984.4277657

Di Tollo, G., \& Roli, A. (2008). Metaheuristics for the Portfolio Selection Problem. International Journal of Operations Research, 5(1), 13-35

Doran, J., \& Wright, C. (2010). What Really Matters When Buying and Selling Stocks: A Survey of Finance Professors' Investing Behavior. Advances in Financial Education, 8(1), 35-61.

Fabozzi, F., Gupta, F., \& Markowitz, H. (2002, Fall). The Legacy of Modern Portfolio Theory. The Journal of Investing, 1(3), 7-22. http://dx.doi.org/10.3905/joi.2002.319510

Geoffrion, A. (1976). The Purpose of Mathematical Programming Is Insight, Not Numbers. Interfaces, 7(1), Part 1 of Two, 81-92. http://dx.doi.org/10.1287/inte.7.1.81

Gigerenzer, G. (2000). Adaptive Thinking. Rationality in the Real World. Oxford: Oxford University Press. http://dx.doi.org/10.1016/s0001-6918(02)00046-x

Gigerenzer, G., \& Shelten, R. (2001). Bounded Rationality: The Adaptive Toolbox. Cambridge (Massachusetts): The MIT Press. http://dx.doi.org/10.1086/345264

Gigerenzer, G., \& Todd, P. (1999). Simple Heuristics That Make Us Smart. Oxford: Oxford University Press. http://dx.doi.org/10.1002/acp.793

Hambrick, D. C, \& Mason, P. A. (1984). Upper echelons: The organization as a reflection of its top managers. Academy of Management Review, 9(2), 193-206. http://dx.doi.org/10.2307/258434

Hogarth, R. M. (1980). Judgment and Choice: The Psychology of Decision. New York: Wiley \& Sons.

Janis, I. L. (1989). Crucial Decisions: Leadership in Policy-making and Crisis Management, New York: Free Press. http://dx.doi.org/10.1177/002194369303000106

Khan, A. (1987). Assessing venture capital investments with non-compensatory behavioral decision models. Journal of Business Venturing, 2,193-205. http://dx.doi.org/10.1016/0883-9026(87)90008-5

Lancaster, K. (1966). A New Approach to Consumer Theory. Journal of Political Economy, 74, 132-157. http://dx.doi.org/10.1086/259131

Markowitz, H. (1952). Portfolio Selection. Journal of Finance, VII(1), 77-91. http://dx.doi.org/10.2307/2975974

Markowitz, H. (1959). Portfolio Selection, Efficient Diversification of Investments. New York: John Wiley \& Sons. http://dx.doi.org/10.7202/1001620ar

Martellini, L, \& Urosevic, B. (2006, June). Static Mean-Variance Analysis with Uncertain Time Horizon. Management Science, 52(6), 955-964. http://dx.doi.org/10.1287/mnsc.1060.0507

Mintzberg, H., Rasinghani, D., \& Theoret, A. (1976). The structure of unstructured decision processes. Administrative Science Quarterly, 21(2), 246-275. http://dx.doi.org/10.2307/2392045

Nofsinger, J. (2011). The Psychology of Investing. Prentice-Hall: New York, 2011.

Prahalad, C. K., \& Bettis, R. A. (1986). The Dominant Logic: A New Linkage between Diversity and Performance. Strategic Management Journal, 7(6), 485 - 501. http://dx.doi.org/10.1002/smj.4250070602

Roy, A. (1952). Safety First and the Holding of Assets. Econometrica, 20, 431-49. http://dx.doi.org/10.2307/1907413

Rubinstein, M. (2002). Markowitz's 'Portfolio Selection': A Fifty-Year Retrospective. The Journal of Finance, LVII(3), 1041-1045. http://dx.doi.org/10.1111/1540-6261.00453

Shepherd, D. A., Zacharakis, A., \& Baron, R. A. (2003). VC's decision processes: evidence suggesting more experience may not always be better., Journal of Business Venturing, 18, 381-401. http://dx.doi.org/10.1016/s0883-9026(02)00099-x

Shrivastava, P., \& Lim, G. (1984). Alternative Approaches to Strategic Analysis of Environments. Working Paper: New York University. 
Simon, H.. (1955). A Behavioral Model of Rational Choice, Quarterly Journal of Economics, 69, 99-188. http://dx.doi.org/10.2307/1884852

Smith, K. (1974). The Major Asset Problem of the Individual Investor. Journal of Contemporary Business, 49-62. Also in Smith, K. Case Problems and Readings: A Supplement for Investments and Portfolio Management. New York: McGraw-Hill 1990, 279-291.

Steinbach, M. (2001). Markowitz Revisited: Mean-Variance Models in Financial Portfolio Analysis. SIAM Review, 43(1), 31-85. http://dx.doi.org/10.1137/s0036144500376650

Stubbart, C. I., \& Ramaprasad, A. (1990). Comments on the Empirical Articles and Recommendations for Future Research, New York: John Wiley \& Sons. In A. S. Huff (ed.), Mapping Strategic Thought, 251-288.

Tarrazo, M. (1997). An Application of Fuzzy Set Theory to the Individual Investor Problem. Financial Services Review, 6(2), 97-107. http://dx.doi.org/10.1016/s1057-0810(97)90021-4

Tarrazo, M. (1999). Fuzzy Sets and the Investment Decision. Financial Technology, (Technology Issue of the Journal of Investing), 37-47.

Tarrazo, M. (2008a). Positive Optimal Weights on the Efficient Frontier: Conditions, Causes, and Implications. The International Journal of Finance, 20(2), 4743-4774.

Tarrazo, M. (2008b). Intervals in Finance and Economics: Bridge Between Words and Numbers, Language of Strategy. Chapter 51 in Handbook of Granular Computing. Witold Pedrycz, Andrzej Skowron \& Vladik Kreinovich, eds. New York, John Wiley \& Sons. http://dx.doi.org/10.1002/9780470724163.ch51

Tarrazo, M. (2009). Identifying Securities to Buy: The Heuristic ri/stdi. Research in Finance, 25, 229-268. http://dx.doi.org/10.1108/s0196-3821(2009)0000025011

Tarrazo, M. (2014). Portfolio Optimization without Programming -Pedagogical and Practical Implications. Advances in Financial Education, 12, 90-122.

Tarrazo, M., \& Ubeda, R. (2012) Minimum-Variance versus Tangent Portfolios-A Comment. Journal of Asset Management, 13, 186-195. http://dx.doi.org/10.1057/jam.2011.21

Tversky, A., \& Kahneman, D. (1974). Judgement under Uncertainty: Heuristics and Biases. Science, 185, 1124-1130. http://dx.doi.org/10.1126/science.185.4157.1124

Weick, K. E. (1979). Social Psychology of Organizing. Reading, MA: Addison-Wesley.

Zacharakis, A., \& Shepherd, D. (2001). The nature of information and overconfidence on venture capitalists' decision making. Journal of Business Venturing, 16, 311-332. http://dx.doi.org/10.1016/s0883-9026(99)00052-x

\section{(cc) $\mathrm{BY}$}

This Work Is Licensed Under A Creative Commons Attribution 3.0 License. 